\title{
The Occupational Role of the Lay Health Trainer in England: A Review of Practice
}

\author{
Rachel Williams ${ }^{1, *}$, Geoff Middleton ${ }^{1}$, Jacquelyn Allen-Collinson ${ }^{1}$, Ros Kane $^{2}$, Adam Coussens ${ }^{1}$ \\ ${ }^{1}$ School of Sport and Exercise Science, University of Lincoln, UK \\ ${ }^{2}$ School of Health and Social Care, University of Lincoln, UK
}

Copyright $\mathrm{O} 2016$ by authors, all rights reserved. Authors agree that this article remains permanently open access under the terms of the Creative Commons Attribution License 4.0 International License

\begin{abstract}
Health Trainers constitute an emergent occupational group in the Public Health system in England with the key purpose to reduce health inequalities by helping or 'nudging' people in local communities to adopt healthier lifestyles. Whilst primarily supplying health-related information and support regarding smoking cessation, diet, alcohol, physical activity and mental wellbeing issues, the role also requires awareness of, and sensitivity toward the specific needs of local communities. This literature review charts current research on the occupational context of the Health Trainer role since its implementation in the English Public Health system. It provides a critical examination of current literature whilst highlighting the theoretical basis of Health Trainers' roles, the potential boundary-crossing nature of their work, along with professional development issues.
\end{abstract}

Keywords Health Promotion, Health Trainer, Community Health Workers, Role-blurring, Career Development

\section{Introduction}

The introduction of the Health Trainer (HT) initiative in 2004 was regarded as one of the most innovative and interesting developments seen in Public Health (PH) policy in England [1]. First proposed in the government white paper, Choosing Health [2], the HT initiative aimed to reduce disease and health inequalities and improve the health behaviour of those living in the most socially-deprived areas in England [3]. Specifically, HTs were introduced to provide health-related information and support regarding smoking cessation, diet, alcohol, physical activity and mental wellbeing issues [4,5]. Although trained and equipped to provide basic health advice to groups and individuals, HTs provide a key point-of-contact for referral to other specialist healthcare services [6,7]. Socially deprived neighbourhoods are classified by the English Indices of Deprivation [8] and are recognised as residential areas that experience particularly high levels of morbidity and mortality. In 2005, twelve Primary Care Trusts (PCTs) deployed the first HT teams in the United Kingdom [2,7]. Since the abolition of PCTs and the national reforms in the English health system [9], local authorities and their PH Directorates currently employ the majority of the HTs in service. In 2011, the HT workforce stood at over 2,790 [10] and since their introduction, it has been reported that 3000 HTs have supported over 500,000 people in England [11].

With focus on the wider determinants of health, community development and expansion of the $\mathrm{PH}$ workforce, it was originally envisaged that HTs would eventually become the 'fundamental building blocks for health improvement' [2,12]. A recent report by the Royal Society of Public Health [11] has highlighted the 'considerable diversity', 'polarisation' and 'complexity' of the HT services that local PH directorates deploy. It is therefore timely to consider the role of HTs, and this narrative review consolidates the current research and perspectives from the HT literature, to establish the dimensions and nature of HTs' contribution to the English PH system.

\section{Materials and Methods}

Studies on HTs were drawn from the literature review search. We searched a range of databases, such as Google Scholar, Sports Discuss and PubMed, to select English language papers relating to HTs and the HT service throughout the United Kingdom. First, eighty research studies were identified from a broad literature search using the terms health trainers, lay workers, community health workers, community health assistants, public health, role blurring, professional development and career progression. Our literature search spanned from 2004 (when the HT initiative was first proposed by government) to the present date, and no limits were placed on the dates of publication. Abstracts resulting from the search were then screened for eligibility and, when appropriate, we assessed the full 
articles. Searches of abstracts and titles were conducted using the names of authors who are well established in the field of Public Health. Furthermore, the reference lists of relevant papers were hand-searched for further publications and search terms, and articles considered in this review did not have any specific criteria in regards to study design or sample. Thirty-seven articles, specifically relating to HTs and the HT service, were included in the final review.

\section{Results/Discussion}

\section{The Theory and Application of the Health Trainer Service}

Working within a health-improvement context, HTs are exhorted to use a psycho-social model of practice $[2,13]$, and trained in specific psychological techniques of support and engagement. Important aspects include the 'Process of Change (Transtheoretical) Model' [14] and 'Social Learning Theory' [15]. The national training programme (City \& Guilds level 3 Certificate for HTs and a level 2 RSPH award in Understanding Health Improvement) draws extensively on health psychology literature as a foundation or theory-base, alongside social support, 'natural helping' and community development $[16,6]$. Focusing on a holistic view of health, HTs are proactive in assisting people with nascent or extant health issues. HTs often work on a one-to-one basis over a 6-to-12-week period in which 'clients' are actively engaged in the process of contact and support [13]. During this time, HTs help clients set planned, manageable goals, using self-monitoring techniques to improve levels of confidence [12,17,18]. As Visram, Clarke, and White [13] explain, the latter is especially important in health interventions that target groups on low incomes, which tend to have a lower confidence and skill base [19]. Although challenging to implement, a powerful 'bottom-up' (non expert-led) approach to health promotion can enhance self-efficacy so people take control and ownership of their own health [20]. The ethos of the HT operation, therefore, differs from the traditional health service, which uses a medical health-promotion model (expert-led) [12,20]. Interestingly, Lloyd [21] reported considerable diversity between HT services, and a divergence from the 'original' service model in providing routine health-checks and support for specific conditions such as chronic pain and diabetes. Whilst some HT services have embraced this move, others have consciously resisted it and placed greater focus on providing a holistic service that is entirely community-based [21].

Socio-environmental factors are widely recognised as influencing health [22,23]. As Phoenix and Grant [24] note, complex, dynamic, changing societal settings often have a strong influence on people's health biographies, and it is important for health interventions to acknowledge the social circumstances influencing lifestyle $[25,26]$. Thus, HTs endeavour to understand and support clients in their own life-world and help people redefine or improve health behaviours and habits that may have a negative impact upon health and wellbeing [5].

Although the foundation of the HT initiative lies in psycho-social theories there have been very few 'robust' evaluations assessing the effectiveness of the service [13]. This has caused concern [27] and increasing demand for work funded by public agencies to become more focused on establishing effectiveness through evaluation [13,28]. HTs have made a very positive difference to the lives of many individuals [21]. The backgrounds of clients and their motivations to change behaviour have been studied but little is known about the effectiveness of HT services in facilitating sustained behaviour change; further investigation is needed [29]. White, Bagnall, and Trigwell [30] highlighted improve ments in clients' self-efficacy, psychological wellbeing and mental health, including amongst the 'hard-to-reach'. Most improvement was seen amongst clients aged 18-25 and in male clients, although positive benefits were noted across gender. Furthermore, Jennings et al. [31] reported positive weight and blood pressure outcomes and health-related behaviours (e.g. healthier eating) with clients from social disadvantaged communities but concluded that further longitudinal research was necessary.

Although empirical evidence specifically relating to HT services' efficacy may be limited, in addition to concerns regarding data collection and reporting processes [32], systematic reviews of similar lay health workers (LHW)/community health workers (CHW) have been found to be 'promising' when deployed as PH services [13,33-35].

\section{Health Trainers as Lay/Community Health Workers}

Acting as a bridge between disadvantaged populations and healthcare systems, LHW/CHW have been utilised internationally and across different settings for at least twenty years $[33,34,36,37]$. Evidence suggests that LHW/CHW are an effective resource in the endeavour to improve PH services such as breast cancer screening, vaccination uptake, smoking cessation, HIV prevention, improving back pain, type 2 diabetes management, and the diagnosis and treatment of acute respiratory infection in children [33-35]. Indeed, LHW/CHW provide important roles in community health $[34,38]$ including as: community food workers [39], peer educators [40,41], breastfeeding support workers [42] and walking-for-health leaders [43]. In relation to the HT context, Visram, Clarke, and White [13] identified a lacuna in the exploration of service-user experiences and views that should inform the development of the initiative. Although there is much advocacy and suggestion that, globally, LHW/CHW have made a positive difference to communities, in a wide range of different settings $[33,34,39]$, there remains insufficient evidence to determine which LHW strategies are likely to be most effective and/or cost-effective [32,44].

The concept of using LHW/CHW is not novel, but has 
only been embraced in mainstream UK health services since the HT policy launch in 2004 [45,46]. Cook and Wills [37] suggest that HTs differ from other community-based LHW roles as they take a more generic approach [47], in facilitating behaviour change in individuals from a number of communities and addressing a range of health issues. In recent times, there are examples of HT roles becoming more specialised in specific settings; for example, in probation settings [48] and with clients from Black and Ethnic Minority (BME) groups, such as Polish populations [49].

HTs are usually lay people from the local community, who are generally low paid and without professional qualifications or specifically trained prior to recruitment as a HT [37]. A HT competence framework was developed and produced by the British Psychological Society and commissioned by the Department of Health [50,51]. HTs are encouraged to complete a specialised City \& Guilds HT Certificate [52] as part of the competence framework. This training provides recruited HTs with the opportunity to gain a formal qualification and begin to progress in the $\mathrm{PH}$ system $[50,51]$. Currently, however, there are no data recording the number of HTs with this level of qualification. Within South and colleagues' [43] extensive literature review on LHW roles, career progression and development have been clearly identified as issues that warrant further investigation. Interestingly, studies have cited several personal and perceived benefits to those employed as a HT despite being a relatively low paid occupation. For example, HTs reported a sense of accomplishment when helping the health and wellbeing of community people [5,7,53] and expressed appreciation of the skills, experience and knowledge they gained [51]. They have also reported increased levels of self-confidence and self-esteem and a sense of fulfilment [54]; these aspects have enhanced HTs' confidence levels and employment progression $[38,51,55]$. To date, there has been limited research exploring the lived or embodied experiences of the HT role using an advanced qualitative inquiry. Indeed, in order to retain HTs, a richer, more in-depth understanding of their roles and motivation is required with consideration of training opportunities, recognition and support [51] amongst other things.

\section{Role Blurring and Tension}

It has been argued by some $[53,56]$ that the HT role can be likened to other non-professional lay health worker roles, vis-à-vis working at the community level and targeting individuals with specific health issues from particular communities [38]. As an innovative type of health worker, HTs have a crucial role in supporting individuals within the community to make healthier lifestyle choices $[3,5]$. The recruitment of HTs from local communities has been a key feature of the initiative [1]. Being an insider to the 'community' gives HTs greater familiarity with shared concerns within the community. This creates an environment whereby HTs are 'in touch' with the living realities of the people with whom they are working [1]. From a social identity approach [57], for example, it has been proposed that if individuals relate to fellow community members as 'us', rather than 'others', this helps define who 'we are' [58]. A shared social identity in the community has been found positively to influence a number of health-related behaviours; for example, when smokers share a salient identity with fellow group members they are less likely to smoke, or be negatively influenced by other smokers $[59,60]$. HTs seek to facilitate communication between community members and other health workers and they have been viewed as a means of translating and conveying important key PH messages to those living in deprived areas [61].

Qualitative research by South, Woodward, and Lowcock [1] identified six different dimensions of the HT role: supporting, listening, emphasising, boosting clients' confidence, helping empower clients and signposting to other healthcare professionals. Although aspects of the HT role were clearly defined, findings from the study highlighted dilemmas regarding the boundaries of the HT role in relation to support and advice, particularly when client expectations for further direction existed [1,5]. Despite a clear administrative and theoretical purpose, the acceptance of the HT as a credible occupation (and as an operable initiative) into the $\mathrm{PH}$ infrastructure in England has not been embedded without tension, especially where there has been a perceived overlap between the roles of HTs and existing health workers [1,27,53,54,62-64]. More recently, attention has been drawn toward the need for professional support, supervision and clinical governance to oversee HT responsibilities [1,5]. In light of the tension faced, it is a poignant time for HTs to ascertain clarity in the profession's role and responsibility in the wider $\mathrm{PH}$ workforce. With non-professional roles becoming more common in the $\mathrm{PH}$ workforce [34], HTs and other LHW/CHW will be working with professionals on a more regular basis [65]. In consequence, concerns on disparities between level of qualifications and wages [66] may intensify.

Initially, the recruitment of HTs from local communities was seen as a positive move by the HT programme stakeholders [1,67], however several studies have illustrated tension between the lay and professional aspect of the role, negatively influencing engagement with marginalised communities $[67,68]$. Researchers have questioned how HTs 'fit into current service provision' [67]. Occupational ambiguity and role tensions $[69,70]$ surround the HT role and the title itself is often misinterpreted by clients, health professionals and also HTs themselves, particularly as they have the potential to work across both professional and lay boundaries. In this respect, HTs have been described in literature as: 'para-professional', 'non-professional' and 'pavement practitioners' [66]. Dugdill and colleagues [66] highlighted the complex nature of the HT role when dealing with extremely challenging client issues, such as: abuse, bereavement, alcoholism, suicide, mental health problems (see also [5]) and debt. The unhealthy behaviours that clients exhibited, according to the study, were often symptomatic of complex underlying issues. HTs simultaneously had to deal 
with unhealthy behaviours as well as the underlying influencing factors, and found these problems demanding and challenging, almost to the point of being overwhelmed. They also expressed increasing concern about overstepping professional boundaries

[66].

Boundary-crossing/permeability issues in inter-professional settings have resulted in role blurring between professions in health domains $[5,71,72]$. Role blurring may be perceived as beneficial by some [71], however, many health professionals oppose it. Linking it to confusion and role strain, health workers can become overwhelmed when trying to do everything simultaneously whilst experiencing uncertainty about the limits of their responsibilities [71,73,74]. This particular aspect is of concern in the current climate given the pressing need to improve the supervision and clinical governance which should oversee the HT role [1,5].

\section{Professional Development and Career Issues}

With regard to entry into the occupation, the HT journey framework [51] highlights personal attributes, experiences, life events and personal motivators as factors which lead individuals to become a HT. Moreover, the framework indicates personal and skill development, benefits to health and wellbeing and strengthening of values as the key elements acquired in the process of being a HT. The last stage in the framework illustrated by Rahman and Wills [51] suggests that in terms of moving forward, HTs can benefit from the continuation of working in a health and wellbeing field, they also have the opportunity to progress to a senior position and mentor new HTs. The framework fails to illustrate, however, any financial increments or professional qualifications associated with the progression to a senior HT position.

Rahman and Wills [51] argue that being a HT often embeds and strengthens individuals' motivation and values, encouraging them to continue working with people and communities in health-related fields, but can also generate frustration due to becoming increasingly anchored in the role with limited support for career progression $[51,75]$. Given intentions to expand the HT workforce [28], this raises concerns about the progress, sustainability and effectiveness of the HT initiative in England. Rahman and Wills [51] assert that for the HT service to act successfully as a ladder to social inclusion, the service must better facilitate the flow of more lay people into HT roles, whilst also supporting the career progression of existing HTs and their work mobility. If supported progression were in place, it would enable HTs to become more professionalised and allow them the opportunity to 'move forward' with their personal careers. Of course this requires support from commissioners, workforce planners, and policy-makers. Their views on the costs of implementing career-progression pathways for HTs, whilst accompanying the intended expansion of the $\mathrm{PH}$ workforce [28], require further research

In circumstances where HTs regularly manage sensitive situations outside their knowledge, experience and control, reflection (both in action and on action) is vital for sharing critical opinions, knowledge and learning from previous mistakes [76]. Health professionals are expected to implement their role/practice based on knowledge of 'what works' and usually work in a climate enabling reflective practice [77]. This often becomes problematic when taking on a new role if the evidence-base is lacking. In addition to individual expertise and skills, Dugdill et al. [66] highlighted the importance for health professionals to understand efficient co-working in inter-professional teams. Zwarenstein and Reeves' [78] review similarly suggested benefits of collaboration in health interventions. Inter-professional collaboration between HTs and more specialist health professionals/services, for example, could allow for information-exchange regarding certain aspects of clients' conditions requiring intervention. Working in an inter-professional environment necessitates understanding of the limits/boundaries within which professionals both should and could operate [66]. Reflective practice can enable health-workers to understand the impact/consequences of their actions [66]. For regulatory bodies, such as the Health Professions Council, reflection is a requirement. In comparison, the HTs Handbook contains no reference to reflective practice, tools to aid reflection or ways of embedding good practice in future HT role development [6]. Dugdill et al. [66] found that HTs have limited systematic ways of reflecting on practice, perhaps as a result of the neglect of formal (critical) reflection as a key skill in health promotion practice [13,79]. Furthermore, there may be challenges in integrating critical reflection in the HT profession as often critical reflexivity is confined to degree programmes and post-study experiences [80]. As HTs are typically without professional healthcare qualifications [67] this may present an obstacle to generating a suitable standard of critical reflection into practice.

\section{Conclusions}

This review has examined the literature surrounding the role of HTs. In terms of health and wellbeing, it is clear that the HT role has 'touched' the lives of many people from disadvantaged communities across England [5,7,53], with the benefits also extending to HTs and their own families $[38,43,55]$. The review has illustrated, however, the ambiguity [66] tensions and contradictions [67,68] associated with HTs' roles, occupational identity, and integration into the wider $\mathrm{PH}$ workforce. Concerns have been expressed in regards to the lack of rigorous evaluative research examining the HT initiative [13]. This review demonstrates the need for in-depth research to explore HTs' lived experiences as well as those of the people who commission, plan and manage HTs, as their perspectives are currently neglected in the literature. The need for critical 
reflection as a tool to enhance practice emerged as salient, as did concerns over career development in this service [51].

\section{Disclosure Statement}

No potential conflict of interest was reported by the author.

\section{REFERENCES}

[1] South, J., Woodward, J., \& Lowcock. D. New beginnings: Stakeholder perspectives on the role of Health Trainers. The Journal of the Royal Society for the Promotion of Health, 127, (5), 224-230, 2007.

[2] DoH Department of Health. Choosing Health: Making Healthy Choices Easier: Public Health White Paper. The Stationary Office, London, 2004.

[3] Trayers, T., \& Lawlor. D. A. Bridging the gap in health inequalities with the help of Health Trainers: A realistic task in hostile environments? A short report for debate. Journal of Public Health, 29, (3), 218-221, 2007.

[4] White, J., Woodward, J., \& South, J. Addressing inequalities in health-what is the contribution of Health Trainers? Perspectives in public health, 133, (4), 213-220, 2013.

[5] RSPH Royal Society for Public Health. Minded to Change: The Link Between Mental Wellbeing and Healthier Lifestyles. 2015b. Online available from: https://www.rsph.org.uk/filem anager/root/site_assets/our_work/reports_and_publications/r sph_dcrs_report_pages_5.11.15.pdf. Accessed January 16, $201 \overline{6}$.

[6] Michie, S., Rumsey, N., Fussell, A., Hardeman, W., Johnston, M., Newman, S., \& Yardley, L. Improving health: changing behaviour. NHS health trainer handbook. Manual: Department of Health Publications (Best Practice Guidance: Gateway Ref 9721), 2008.

[7] Bailey, D., \& Kerlin. L. Can Health Trainers make a difference with difficult-to-engage clients? A multisite case study. Health Promotion Practice, 1-9, 2015.

[8] DCLG Department for Communities and Local Government. English Indices of Deprivation, 2015. Online available from: https:/www.gov.uk/government/uploads/system/uploads/att achment_data/file/465791/English_Indices_of_Deprivation 2015_-_Statistical_Release.pdf. Accessed January 27, 2016.

[9] DoH Department of Health. The White Paper. Equity and excellence: liberating the NHS. Department of Health, London, 2010.

[10] Fidan, E., \& Hopkinson, D. DCRS National Report 2011/12 Health Trainer Services Review. Birmingham: DCRS Support Team, Birmingham and Solihull NHS, 2011.

[11] RSPH Royal Society for Public Health. Indicators of change: The adaption of the Health Trainer service in England. 2015a. Online available from: http://healthtrainersengland.com/wpcontent/uploads/2014/06/RSPH-HT-report-2015.pdf. Accessed January 16, 2016.
[12] Shircore, R. Health Trainers half year review $1^{\text {st }}$ April $-30^{\text {th }}$ September 2013. Royal Society for Public, 3-23, 2013.

[13] Visram, S., Clarke, C., \& White, M. Making and maintaining lifestyle changes with the support of a lay health advisor: longitudinal qualitative study of health trainer services in northern England. PLOSone, 9, (5), 2014.

[14] Prochaska, J. O. Changing for good. Avon Books, New York, 1994.

[15] Bandura, A. Self-efficacy: The Exercise of Control. Freeman, New York, 1997.

[16] Eng, E., Parker, E., \& Harlan. C. Lay health advisor intervention strategies: A continuum from natural helping to paraprofessional helping. Health Education \& Behaviour, 24, (4), 413-417, 1997.

[17] Shilts, M, K., Horowitz, M., Townsend. M. S. Goal setting as a strategy for dietary and physical activity behaviour change: A review of the literature. American Journal of Health Promotion, 19, (2), 81-93, 2004.

[18] Abraham, C., \& Michie, S. A taxonomy of behaviour change techniques used in interventions. Health Psychology, 27, (3), 379-387, 2008.

[19] Michie, S., Jochelson, K., Markham, W., \& Bridle, C. Low-income groups and behaviour change interventions: A review of intervention content, effectiveness and theoretical frameworks. Journal of Epidemiology and Community Health, 63, 610-622, 2009.

[20] Naidoo, J., \& Wills, J. Foundations for health promotion. Health Sciences, Elsevier, 2009.

[21] Lloyd, E. Health Trainers: A service in transition. Perspectives in Public Health, 135, (2), 64, 2015.

[22] Barton, H., \& Grant. M. A health map for the local human habitat. The Journal for the Royal Society for the Promotion of Health, 126, (6), 252-253, 2006.

[23] Marmot, M., Friel, S., Bell, R., Houweling, T. A. J., \& Taylor, S. Closing the gap in a generation: Health equity through action on the social determinants of health. The Lancet, 9650, (372), 1661-1669, 2008.

[24] Phoenix, C., \& Grant, B. Expanding the agenda for research on the physically active aging body. Journal of Aging Physical Activity, 17, (3), 362-379, 2009.

[25] Marmot, M. Social determinants of health inequalities. The Lancet, 365, (9464), 1099-1104, 2005.

[26] Lee, J. E. C., Lemyre, L., Turner, M. C., Orpana, H. M., \& Krewski, D. Health risk perceptions as mediators of socioeconomic differentials in health behaviour. Journal of Health Psychology, 13, (8), 1082-1091, 2008.

[27] Attree, P., Clayton, S., Karunanithi, S., Nayak, S., Popay, J., \& Read, D. NHS Health Trainers: A review of emerging evaluation evidence. Critical Public Health, 22, (1), 25-38, 2012.

[28] RSPH Royal Society for Public Health. Rethinking the Public Health Workforce. 2015c. Online available from: http://www.rsph.org.uk/filemanager/root/site_assets/our_wor $\mathrm{k} /$ wider_public_health_workforce/rsph_widerworkforce_rep ort_final.pdf. Accessed January 15, 2016. 
[29] Wilkinson, D., Sniehotta, F., \& Michie, S. Targeting those in need: Baseline data from the English National Health Service (NHS) Health Trainer service. Psychology Health \& Medicine, 16, (6), 1-13, 2011.

[30] White, J., Bagnall, A-M., \& Trigwell, J. Health Trainers making a difference to mental health and wellbeing. Perspectives in Public Health, 135, (3), 130-132, 2015.

[31] Jennings, A., Barnes, S., Okereke, U., \& Welch, A. Successful weight management and health behaviour change using a Health Trainer model. Perspectives in Public Health 133, (4), 221-226, 2013.

[32] Mathers, J., Taylor, R., \& Parry, J. Measuring the impact of Health Trainers services on health and health inequalities: Does the service's data collection and reporting system provide reliable information? Journal of Public Health, 1-6, 2016.

[33] Lewin, S. A., Babigumira, S. M., Bosch-Capblanch, X., Aja, G., Van Wyk, B., Glenton, C., Scheel, I., Zwarenstein, M., \& Daniels, K. Lay Health Workers in Primary and Community Health Care: A Systematic Review of Trials. World Health Organization, Geneva, 2006.

[34] Viswanathan, M., Kraschnewski, J., Nishikawa, B., Morgan, L. C., Thieda, P., Honeycutt, A., Lohr, K. N., \& Jonas, D. Outcomes of community health worker interventions. University of North Carolina, North Carolina, 2009.

[35] Carr, S., Lhussier, M., Forster, N., Geddes, L., Deane, K., Pennington, M., Visram, S., White, M., Michie, S., Donaldson, C., \& Hildreth, A. An evidence synthesis of qualitative and quantitative research on component intervention techniques, effectiveness, cost-effectiveness, equity and acceptability of different versions of health-related lifestyle advisor role in improving health [briefing paper]. Health Technology Assessment, 15, (9), 1-284, 2011.

[36] Walt, G. Community Health Workers in National Programmes: Just another Pair of Hands? Open University Press, Milton Keynes, 1990.

[37] Cook, T., \& Wills, J. Engaging with marginalized communities: The experiences of London Health Trainers. Perspectives in Public health, 132, (5), 221-227, 2012.

[38] South, J., White, J., \& Gamsu, M. People-Centred Public Health, 1st ed. The Policy Press, Bristol, 2012.

[39] Kennedy, L. A., Milton, B., \& Bundred, P. Lay food and health worker involvement in community nutrition and dietetics in England: Roles, responsibilities and relationship with professionals. Journal of Human Nutrition and Dietetics, 21, (3), 210-224, 2008.

[40] Cuijpers, P. Peer-led and adult-led school drug prevention: A meta-analytic comparison. Journal of Drug Education, 32, (2), 107-119, 2002

[41] Mellanby, A., Rees, J., \& Tripp, J. Peer-led and adult-led school health education: A critical review of available comparative research. Health Education Research, 15, (5), $533-545,2000$.

[42] Fairbank, L., O'Meara, S., Renfrew, M. J., Woolridge, M., Sowden, A. J., \& Lister-Sharp, D. A systematic review to evaluate the effectiveness of interventions to promote the initiation of breastfeeding. Health Technology Assessment, 4, (25), 71, 2000.
[43] South, J., Meah, A., Bagnall, A., Kinsella, K., Branney, P., White, J., \& Gamsu, M. People in Public Health - a study of approaches to develop and support people in public health roles. Project Report. Report for the National Institute for Health Research Service Delivery and Organisation Programme, Leeds Metropolitan University, 2010.

[44] Visram, S., Carr, S. M., \& Geddes. L. Can lay Health Trainers increase uptake of NHS health checks in hard-to-reach populations? A mixed-method pilot evaluation. Journal of Public Health, 37, (2), 226-223, 2014.

[45] Scorer, C. Health Trainers implementing a new public health role. The Journal of the Royal Society for the Promotion of Health, 127, (6), 258-9, 2007.

[46] Gidlow, C. J., Cochrane, T., Davey, R., Beloe, M., Chambers, R., Kumar, J., Mawby, Y., \& Iqbal, Z. One-year cardiovascular risk and quality of life changes in participants of a Health Trainer service. Perspectives in Public Health, 134, (3), 135-44, 2013.

[47] Skills for Health. Competencies for Health Trainers (Version 1.7). Skills for Health, London, 2006.

[48] Dooris, M., McArt, D., Hurley, M., \& Baybutt, M. Probation as a setting for building well-being through integrated service provision: Evaluating an offender Health Trainer service. Perspectives in Public Health, 2013.

[49] Kime, N. H., South, J., \& Lowcock, D. An Evaluation of the Bradford District Health Trainers Programme - Phase 2. Leeds: Centre for Health Promotion Research, Leeds Metropolitan University, 2008.

[50] DoH Department of Health. Improving Health: Changing Behaviour: NHS Health Trainer Handbook. The Stationery Office, London, 2008.

[51] Rahman, E., \& Wills, J. The career journeys of Health Trainers in two Health Trainer services in England. Perspectives in Public Health, 133, (4), 207-212, 2013.

[52] C\&G City \& Guilds. Level 3 certificate for Health Trainers (7562). 2016. Online available from: http://www.cityandguilds.com/qualifications-and-apprentice ships/health-and-social-care/health/7562-health-trainers\#tab =information. Accessed January 27, 2016.

[53] Visram, S., \& Geddes, L. What Does it Mean to Be a NHS Health Trainer? Further Evaluation of the Health Trainers Initiative in County Durham and Tees Valley: Final Report. Northumbria University, Newcastle, 2007.

[54] South, J., Woodward, J., Lowcock, D., \& Woodall, J. An Evaluation of the Bradford District Health Trainers Programme - An Early Adopter Site. Leeds: Centre for Health Promotion Research, Leeds Metropolitan University, 2006.

[55] South, J., Jackson, K., \& Warwick-Booth. L. The community health apprentice project: The outcomes of an intermediate labour market project in the community health sector. Community, Work and Family, 14, (1), 1-18, 2011.

[56] Crane, S., \& Harper. T. South Central Health Trainer Hub Health Trainer Services: Final Evaluation Report: Final Report. Portsmouth: NHS Education South Central, 2008.

[57] Tajfel, H. Experiments in a Vacuum. In The Context of Social Psychology; A Critical Assessment, edited by J. Israel and $\mathrm{H}$. Tajfel, 69-119. Academic Press, London, 1972. 
[58] Haslam, S. A., Jetten, J., Postmes, T., \& Haslam, C. Social identity, health and wellbeing: An emerging agenda for applied psychology. Applied Psychology, 58, (1), 1-23, 2009.

[59] Kobus, K. Peers and adolescent smoking. Addiction, 98, 37-55, 2003.

[60] Schofield, P. E., Pattison, P. E., Hill, D. J., \& Borland, R. Youth culture and smoking: Integrating social group processes and individual cognitive processes in a model of health-related behaviours. Journal of Health Psychology, 8, (3), 291-306, 2003.

[61] Kitchen, G. Health Trainers in Cheshire and Merseyside. HM Partnership, Liverpool 2009.

[62] Ball, L. Evaluation of the North East Lincolnshire Health Trainer Programme: Final Report. Sheffield: Centre for Health and Social Care Research, Sheffield Hallam University, 2008.

[63] Ball, L., O'Kasheh, R. \& Qutishat, D. Evaluation of Health Trainers Working in Primary Care. Sheffield: Centre for Health and Social Care Research, Sheffield Hallam University, 2009a.

[64] Ball, L., O'Kasheh, R., \& Whitfield, M. Summary Evaluation of the North East Lincolnshire Health Trainer Services. Sheffield: Centre for Health and Social Care Research, Sheffield Hallam University, 2009b.

[65] Drinkwater, C. Breaking boundaries: Reinventing general practice for the 21 st century. British Journal of General Practice, 63, (613), 400-401, 2013.

[66] Dugdill, L., Coffey, M., Coufopoulos, A., Byrne, K., \& Porcellato. L. Developing new community health roles: Can reflective learning drive professional practice? Reflective practice, 10, (1), 121-130, 2009.

[67] Ball, L., \& Nasr, N. A. Qualitative exploration of a Health Trainer programme in two UK primary care trusts. Perspectives in Public Health, 131, (1), 24-31, 2010.

[68] Ward, L., \& Banks, L. Evaluation of Health Trainers in West Sussex. University of Brighton, Brighton, 2009.

[69] Allen-Collinson, J. Just 'non-academics'? Research administ rators and contested occupational identity. Work, Employment \& Society, 20, (2), 267-288, 2006.
[70] Allen-Collinson, J. Negative 'marking'? University research administrators and the contestation of moral exclusion. Studies in Higher Education, 34, (8), 941-954, 2009.

[71] Brown, B., Crawford, P., \& Darongkamas, J. Blurred roles permeable boundaries: The experience of multidisciplinary working in community mental health. Health Social Care and Community, 8, (6), 425-435, 2000.

[72] MacNaughton, K., Chreim, S., \& Bougeault, I. Role construc tion and boundaries in interprofessional health care teams: A qualitative study. BMC Health Services Research, 13, (1), $1-23,2013$

[73] Hall, P. Inter-professional teamwork: Professional cultures as barriers. Journal of Interprofessional Care, 19, (1), 188-196, 2005.

[74] Belanger, E., \& Rodriguez, C. More than the sum of its parts? A qualitative research synthesis on multi-disciplinary primary care teams. Journal of Interprofessional Care, 22, (6), $587-597,2008$.

[75] Iggulden, P., \& Pratt, A. Peninsula Health Trainer Services 2009 Evaluation Report. South West: South West Health Trainer Partnership, 2010.

[76] Hoyrup, S. Reflection as a core process in organisational learning. The Journal of Workplace Learning, 16, (8), 442-454, 2004.

[77] Marks, D. F. Perspectives on Evidence-based Practice. Health Development Agency, London, 2002.

[78] Zwarenstein, M., \& Reeves. S. Knowledge translation and interprofessional collaboration: Where the rubber of evidence-based care hits the road of teamwork. Journal of Continuing Education in the Health Professions, 26, (1), 46-54, 2006.

[79] Fleming, P. Reflection - a neglected art in health promotion. Health Education Research, 22, (5), 658-664, 2007.

[80] Kilgour, L., Matthews, N., \& Crone, D. Enhancing the Skills of Students through the use of Reflective Practice in a Physical Activity and Health Curriculum. In Reflective Practice in the Sport and Exercise Sciences, edited by Zoe Knowles, David Gilbourne, Brendon Cropley, and Lindsey Dugdill, 69-80. Routledge, Abingdon, 2014. 